\title{
PRODUCTION OF SILICA GEL FROM RESIDUAL RICE HUSK ASH
}

\section{Samantha Pinheiro Buás de Lima}

Faculdade de Tecnologia, Universidade Federal do Amazonas, Av. Gal. Rodrigo Octávio Jordão Ramos, 3000, 69077-000 Manaus-AM, Brasil Raimundo Pereira de Vasconcelos e Otávio Augusto Paiva

Departamento de Construção, Universidade Federal do Amazonas, Campus Universitário - Setor Norte, Coroados I, 69077-001 Manaus - AM, Brasil

\section{Guilherme Chagas Cordeiro*}

Laboratório de Engenharia Civil, Universidade Estadual do Norte Fluminense Darcy Ribeiro, Av. Alberto Lamego, 2000, 28013-602 Campos dos Goytacazes - RJ, Brasil

\section{Márcia Rodrigues de Morais Chaves}

Departamento de Engenharia Química, Escola Politécnica, Universidade de São Paulo, Av. Prof. Lineu Prestes, 580, Bl. 18, 05424-970 São Paulo - SP, Brasil

\section{Romildo Dias Toledo Filho e Eduardo de Moraes Rego Fairbairn}

Instituto Alberto Luiz de Coimbra de Pós-graduação e Pesquisa de Engenharia, Universidade Federal do Rio de Janeiro, CP 68506, 21941-972 Rio de Janeiro - RJ, Brasil

Recebido em 11/2/10; aceito em 24/7/10; publicado na web em 26/11/10

\begin{abstract}
PRODUCTION OF SILICA GEL USING RESIDUAL RICE HUSK ASH. This paper presents a study on the production of silica gel in hydrothermal process using residual rice husk ash. Measurements of the chemical composition, X-ray diffraction, infrared spectroscopy, particle size distribution, and pozzolanic activity were carried out in order to characterize the obtained material, and the optimal silica gel was selected for use as a mineral additive in cement pastes. The compressive strengths were determined for cement pastes containing silica gel $(0.0,2.5$ or $5 \%$ by mass $)$ in different times. The results indicate that the mixtures containing silica gel showed improved mechanical behavior over all time periods evaluated.
\end{abstract}

Keywords: silica gel; sol-gel; rice husk ash.

\section{INTRODUCTION}

Silica gel is a synthetic silica compound that can be extracted from rice husk ash by the sol-gel method. Silica is removed from residual ash in the form of sodium silicate, and in a later stage of the process, treatment with acid converts the silica into gel. This type of extraction can be done at ambient temperatures, making it an alternative to the thermal treatment, which is often used in the production of highly reactivate pozzolanas. ${ }^{1-5}$ Previous studies on the preparation and characterization of extracted silica gel from rice husk ash have resulted in a simplified method for obtaining pure silica, ${ }^{6-9}$ and this process is called the sol-gel method.

The sol-gel method involves the synthesis of an inorganic polymer network by means of chemical reactions in solution at low temperatures. In this process, a colloidal suspension or solution is transformed into gel by establishing bonds between the particles or between molecular specimens. ${ }^{10}$ The materials obtained through this method exhibit high levels of purity and homogeneity, and furthermore, they require processing temperatures much lower than those required to obtain reactive silica from rice husk ash. The chemistry of the sol-gel process is based on the hydrolysis and condensation of molecular precursors.

Silica gel is an inorganic and amorphous polymer that is formed by the condensation of silicate tetrahedrons using oxygen as the binding site, giving rise to the siloxane bond ( $\mathrm{Si}-\mathrm{O}-\mathrm{Si}$ ) and, ultimately, nanometer-sized particles. ${ }^{11}$ The siloxane groups are in the interior of the particles, and the surface is composed of silanol groups

*e-mail: gcc@uenf.br
(Si-OH). Based on previous studies, ${ }^{6-9,11}$ it is known that amorphous silica has increased solubility in solutions with $\mathrm{pH}$ values higher than 10. Therefore, the amorphous silica contained in the rice husk ash can be solubilized when treated with a sodium hydroxide solution that has a $\mathrm{pH}$ value greater than 10 . Thus, amorphous silica is dissolved and forms soluble silicate, which has a solubility of $876 \mathrm{mg} / \mathrm{L}$ in water at $25{ }^{\circ} \mathrm{C} .{ }^{12}$ When solubilized, the silica is in the monomeric form of silicic acid - $\mathrm{Si}(\mathrm{OH})_{4}$, as shown in Equation 1.13

$$
\left(\mathrm{SiO}_{2}\right)_{\mathrm{x}(\mathrm{s})}+2 \mathrm{H}_{2} \mathrm{O}_{(\mathrm{l})} \rightarrow\left(\mathrm{SiO}_{2}\right)_{\mathrm{x}-1(\mathrm{~s})}+\mathrm{Si}(\mathrm{OH})_{4(\text { aq. })}
$$

When sodium silicate is acidified, a supersaturated solution of $\mathrm{Si}(\mathrm{OH})_{4}$ monomers is formed, as described by Equation 2. ${ }^{13}$

$$
\mathrm{Na}_{2} \mathrm{SiO}_{3}+\mathrm{H}_{2} \mathrm{O}+2 \mathrm{HCl} \rightarrow \mathrm{Si}(\mathrm{OH})_{4}+2 \mathrm{NaCl}
$$

The silica gel is formed during the gelification of a silicic acid solution by means of a polymerization process, which is divided into three phases: monomer polymerization to form particles; particle growth; and particle union in ramified chains that extend throughout the solution, which increases the viscosity and forms a gel.

The use of nanosized particles in Portland cement-based materials affects the microstructure and the properties of the cementitious materials that are responsible for increasing the liquid phase viscosity, reducing segregation, increasing workability, filling the voids between the cement grains (filler effect) $)^{14}$ and accelerating the hydration reactions. ${ }^{15}$ These processes favor the formation of small calcium hydroxide crystals and hydrated calcium silicate clusters (C-S-H, in 
accordance with notation used in the chemistry of cement: $\mathrm{C}=\mathrm{CaO}$; $\mathrm{S}=\mathrm{SiO}_{2} ; \mathrm{H}=\mathrm{H}_{2} \mathrm{O}$ ).

Thus, the purpose of this study was to produce silica gel from rice husk residual ash and to investigate the effects of adding this material to Portland cement. The properties of the cementitious pastes were evaluated, with a focus on the development of compressive strength in time.

\section{EXPERIMENTAL}

\section{Materials}

The rice husk ash used for silica gel extraction was collected from the Arroz Urbano Industry, which is located in the municipality of Jaraguá do Sul, in Santa Catarina, Brazil. Grinding of the ash (carried out to improve the silica extraction) was performed for $30 \mathrm{~min}$ using a rotating ball mill. ${ }^{16}$

The chemical composition of the rice husk residual ash, determined by X-ray fluorescence spectroscopy, and the loss on ignition measurement at $950{ }^{\circ} \mathrm{C}$ are shown in Table 1 . Silicon dioxide is the predominant compound (82.6\%), and other oxides are present in significant quantities, including $\mathrm{K}_{2} \mathrm{O}(1.8 \%), \mathrm{P}_{2} \mathrm{O}_{5}(0.9 \%)$ and $\mathrm{MgO}$ $(0.7 \%)$. The elevated level of silica was quantified in $49 \%$ amorphous silica and $33.6 \%$ of $\alpha$-cristobalite by quantitative XRD analysis using the Rietveld method. ${ }^{16}$ The particle size distribution of the ash is illustrated in Figure 1, which shows that after grinding, the ash presents an average particle size $\left(50 \%\right.$ passing size $\left.-D_{50}\right)$ of $16.5 \mu \mathrm{m}$.

Table 1. The chemical composition (\% mass) of the rice husk residual ash and of the Portland cement

\begin{tabular}{lcc}
\hline Compound & Rice husk ash & Portland cement \\
\hline $\mathrm{SiO}_{2}$ & 82.6 & 20.1 \\
$\mathrm{Al}_{2} \mathrm{O}_{3}$ & 0.4 & 5.5 \\
$\mathrm{Fe}_{2} \mathrm{O}_{3}$ & 0.5 & 2.7 \\
$\mathrm{CaO}$ & 0.9 & 64.4 \\
$\mathrm{~K}_{2} \mathrm{O}$ & 1.8 & - \\
$\mathrm{MnO}$ & 0.3 & - \\
$\mathrm{SO}_{3}$ & $<0.1$ & 3.0 \\
$\mathrm{MgO}$ & 0.7 & 1.2 \\
$\mathrm{P}_{2} \mathrm{O}_{5}$ & 0.9 & - \\
Loss on ignition & 11.9 & 3.0 \\
\hline
\end{tabular}

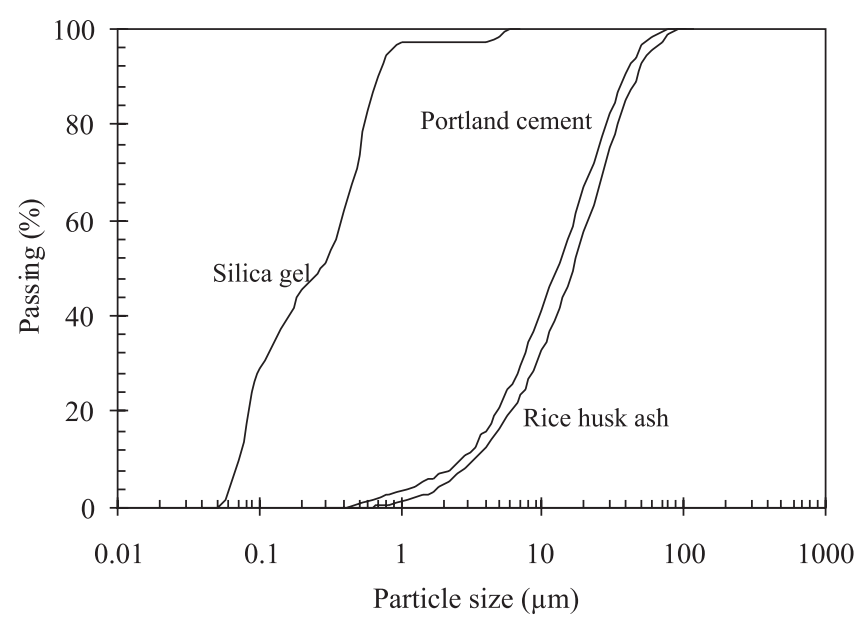

Figure 1. Particle size distributions of the rice husk ash (after grinding), Portland cement and silica gel
In addition to distilled and deionized water, the following reagents (analytical grade) were used for the silica extraction: hydrochloric acid $(\mathrm{HCl})$, sodium hydroxide $(\mathrm{NaOH})$ and ethyl alcohol $\left(\mathrm{C}_{3} \mathrm{H}_{6} \mathrm{O}\right)$. For production of the cement pastes, ordinary Portland cement $(\mathrm{CP}$ I) was used (NBR 5732/1991), ${ }^{17}$ similar to ASTM type I cement, deionized water and superplasticizer admixture polycarboxylatebased Basf Glenium ${ }^{\circledR} 51$ (aqueous solution with $32.6 \%$ solids). The chemical composition and particle size distribution of the cement are shown in Table 1 and Figure 1, respectively.

\section{Extraction and characterization of the silica gel}

Silica gel extraction was carried out in three steps, as indicated by the flowchart in Figure 2: cleaning of the rice husk residual ash with hydrochloric acid $(\mathrm{HCl}) 3 \% \mathrm{v} / \mathrm{v}$; extraction of the silica in the form of sodium silicate; and formation of gel by reducing the $\mathrm{pH}$ of the sodium silicate solution. ${ }^{9}$ For steps 1 and 9 of the silica gel extraction process (Figure 2), $\mathrm{HCl}$ was used because it promotes removal of metal impurities. ${ }^{18}$ In steps 2 and 6, the samples were heated until boiling and were vigorously agitated. For the cooling described in steps 3 and 7, the samples were left at ambient temperature until the temperature equalized. The filtering that was mentioned in steps 4 and 8 was performed using a vacuum pump and Whatmann 41 filter paper. In step 5, the ash was treated with sodium hydroxide $1 \mathrm{M}$ to solubilize the silica present in the sample, thus producing sodium silicate. The formation of the gel, or gelification, was obtained by reducing the $\mathrm{pH}$ (using $\mathrm{HCl}$ ) of the sodium silicate solution with constant agitation to neutral or acidic pH. In step 10 (Figure 2), gel disintegration or breaking was accomplished with a glass rod. The washing step was performed by adding distilled water and then agitating the solution vigorously. The water was discarded, and this process was repeated (four times) until the sodium chloride (produced at the end of the process) was removed from the sample. Complete removal of the salt was verified by the X-ray diffraction analysis.

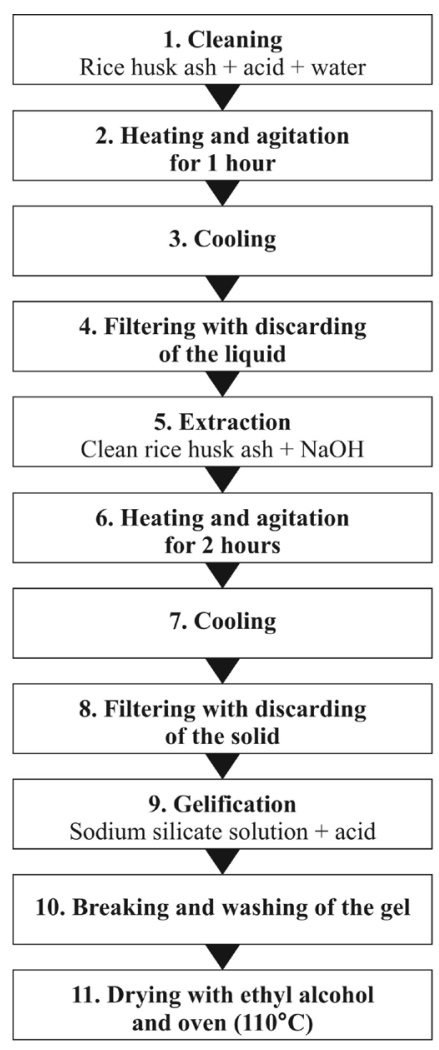

Figure 2. The silica gel extraction process 
Table 2. The silica gel extraction yield and the parameters used in the process

\begin{tabular}{|c|c|c|c|c|c|c|c|c|}
\hline \multicolumn{2}{|l|}{ Parameters } & Gel 1 & Gel 2 & Gel 3 & Gel 4 & Gel 5 & Gel 6 & Gel 7 \\
\hline \multicolumn{2}{|c|}{ Rice husk residual ash (g) } & 50.5 & 50.5 & 50.5 & 50.5 & 50.5 & 83.75 & 50.5 \\
\hline \multirow[t]{2}{*}{ Cleaning } & Deionized water (mL) & 500 & 500 & 500 & 500 & 500 & 500 & 500 \\
\hline & $\mathrm{HCl}(\mathrm{mL})$ & 15 & 15 & 15 & 15 & 15 & 15 & 15 \\
\hline \multirow[t]{4}{*}{ Extraction } & $\mathrm{NaOH} /$ Concentration (M) & 1 & 2 & 2 & 1 & 2 & 1 & 1 \\
\hline & and volume (mL) & 500 & 500 & 500 & 500 & 500 & 500 & 500 \\
\hline & Obtained silicate (mL) & 350 & 350 & 350 & $\mathrm{NO}$ & $\mathrm{NO}$ & $\mathrm{NO}$ & $\mathrm{NO}$ \\
\hline & Volume (mL) & 500 & 500 & 450 & 1000 & 1000 & 1000 & 500 \\
\hline \multirow[t]{4}{*}{ Gelification } & $\mathrm{HCl}(\mathrm{mL})$ & 33 & 61 & 66 & 34 & 65 & 25 & 25 \\
\hline & $\mathrm{pH}$ & 2 & 11 & 2 & 8 & 9 & 10 & 9 \\
\hline & $\begin{array}{l}\text { Time of gelification } \\
\text { (min.) }\end{array}$ & Instantaneous & Moderate & Moderate & 2.0 & 3.0 & 3.0 & Instantaneous \\
\hline & Observation & Turbid gel & $\begin{array}{l}\text { Precipitated } \\
\text { formation }\end{array}$ & $\mathrm{NO}$ & $\mathrm{NO}$ & $\mathrm{NO}$ & $\begin{array}{l}\text { Rigid and } \\
\text { white gel }\end{array}$ & $\begin{array}{l}\text { Rigid and } \\
\text { white gel }\end{array}$ \\
\hline \multicolumn{2}{|l|}{ Yield* $(\%)$} & 31.0 & 21.9 & $\mathrm{NO}$ & 18.2 & 10.9 & 27.5 & $\mathrm{NO}$ \\
\hline
\end{tabular}

NO: Not observed; $*$ In relation to the ash chemical composition $\left(\mathrm{SiO}_{2}=83 \%\right)$.

Water quantity in a Portland cement-based compound must be controlled so as to not compromise its mechanical and durability properties. Thus, in this study, ethyl alcohol was used to reduce the humidity of the gel (step 11). Infrared spectroscopy analyses were performed to verify the total removal of ethanol from the silica gel. A Perkin-Elmer Precisely Spectrum 100 instrument was used in this analysis.

The pozzolanic activity of the silica contained in the gel was determined by the modified Chapelle method. ${ }^{19,20}$ Briefly, this method involves heating (to $90{ }^{\circ} \mathrm{C}$ ) a solution (containing $1.000 \mathrm{~g}$ calcium oxide, $1.000 \mathrm{~g}$ ash and $250.0 \mathrm{~g}$ water free of carbon dioxide) with agitation for $16 \mathrm{~h} .{ }^{20}$ The results of this process are expressed as the quantity of calcium oxide that was consumed or fixed per gram of pozzolanic material ( $\mathrm{mg} \mathrm{CaO} / \mathrm{g}$ pozzolan). A helium pycnometer (Accupyc pycnometer from Micromeritics) was used to determine the specific mass of the cement and dry silica gel (xerogel). Granulometry measurements were carried out in the Zetasizer Nano ZS laser difraction particle size analyzer (Malvern Mastersizer), and the chemical composition was determined by X-ray fluorescence spectroscopy using a Shimadzu EDX 720 instrument. The equipment used in the X-ray diffraction analyses of the silica xerogel samples was a LabX XRD-6000 Shimadzu diffractometer, with monochromatic copper radiation, operating at $40 \mathrm{kV}$ and $30 \mathrm{~mA}$. To determine the phases, the scans were completed with an angular speed of $0.02^{\circ}$ per second and at measured intervals between the Bragg angle $(2 \theta)$ ranging from $5^{\circ}$ to $80^{\circ}$. The morphologic analyses for the present study were performed with a scanning electron microscope Jeol JSM 6460LV, with detection of images from secondary electrons.

\section{Preparation and characterization of the cement pastes}

Studies on the cement pastes were conducted in mixtures with water-solid (w/s in weight basis) ratios equal to 0.45 and 0.50 . The amount of Portland cement that was replaced by silica gel was 0.0 , 2.5 or $5.0 \%$ by mass. The pastes are denoted as pi-y, where $i=\{1,2\}$ for the pastes with w/s equal to 0.45 and 0.50 , respectively, and $y=$ $\{0.0,2.5,5.0\}$ represents the substitution rates. For the $\mathrm{p} 2$ pastes, the $2.5 \%$ substitution was not used. The substitution rates were defined from the fact that $330 \%$ humidity was exhibited at the end of the silica gel extraction process.
The pastes were prepared using a Chandler Engineering rotary mixer. The mixing was carried out for $6 \mathrm{~min}$ at a rotation speed of 4000 $\mathrm{rpm}$ and then for $2 \mathrm{~min}$ at $6000 \mathrm{rpm}$. For the compressive strength tests, four cylindrical specimens were molded $(2.5 \mathrm{~cm}$ in diameter and $5 \mathrm{~cm}$ in height) for each age (3, 7 and 28 days of curing). Molding was done in two layers and each layer was homogenized manually for $30 \mathrm{~s}$ with a glass rod. Curing was performed at a temperature of $22{ }^{\circ} \mathrm{C}$ in water that was saturated with lime. The compressive strengths of the pastes were obtained by rupturing the specimens in a servocontrolled UH-F1000kNI Shimadzu testing machine, with a displacement speed of $0.1 \mathrm{~mm} / \mathrm{min}$. The compressive strength values were statistically evaluated in order to analyze the significance of the different gel concentrations in the cement matrix. Thus, the analysis of variance (ANOVA) at the $5 \%$ probability level $(\mathrm{p}<0.05)$ and the average test (Tukey test) were employed.

\section{RESULTS AND DISCUSSION}

\section{Characterization of the silica gel}

Table 2 shows the yields that were obtained with the gelifications in this study, as well as a summary of the materials that were used in each process. The greatest silica yield (31.0\%) was obtained with gel 1 (500 mL silicate with $1 \mathrm{M} \mathrm{NaOH})$. Therefore, this experimental procedure was adopted for the production of silica gel for the cement pastes. It is important to note that the rice husk ash used for the production of gel 1 was composed of $83 \%$ silica (by mass).

The presence of ethanol in the silica gel samples was detected by infrared spectroscopy (Figure 3). It is important that the alcohol does not interfere with the silica gel characteristics, and therefore complete removal is necessary so that the alcohol mass is not computed as water mass. Infrared spectroscopic analyses were performed on two different gels: gel with humidity reduced to approximately $330 \%$ with ethanol and gel without ethanol (600\% humidity). The characteristic bands observed in the infrared spectrum of the alcohols are due to the stretching or flexing of O-H $\left(1420 \mathrm{~cm}^{-1}\right)$ and $\mathrm{C}-\mathrm{H}\left(1330 \mathrm{~cm}^{-1}\right)$ bonds, and these bands are heavily influenced by hydrogen bonds and by the position of the group in the molecule. In this study is possible to observe the absence of ethanol in the two gels (a magnification of the spectrum in the region characteristic of ethanol is shown in Figure 


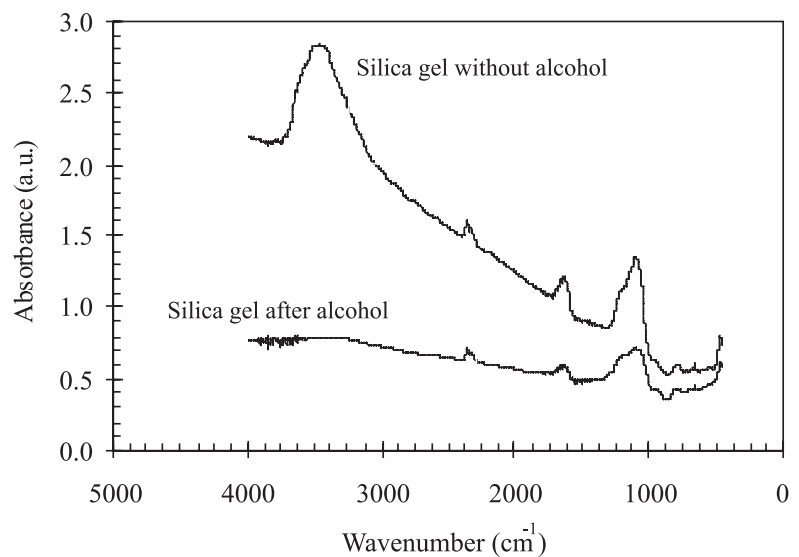

Figure 3. The infrared spectroscopy analysis of the silica gel

1S, supplementary material). The lack of absorption in the 1815-1785 $\mathrm{cm}^{-1}$ region (corresponding to $\mathrm{Cl}$ ) shows that no $\mathrm{NaCl}$ remains after washing the gel (Figure 3).

With regard to the pozzolanic activity, the silica gel presented a calcium hydroxide consumption of $787 \mathrm{mg} / \mathrm{g}$ of silica. This result surpasses (by about $140 \%$ ) the minimum value attributed to pozzolanic materials $\left(330 \mathrm{mg} / \mathrm{g}\right.$ ) by Raverdy et al.. ${ }^{19}$ As a comparison, an ultrafine ash of the rice husk presented pozzolanic activity equal to $736 \mathrm{mg} / \mathrm{g}$ for an average particle size of about $5 \mu \mathrm{m},{ }^{14}$ while a pozzolanic ash from the thermal treatment of the sugar cane bagasse presented a pozzolanic activity equal to $421 \mathrm{mg} / \mathrm{g} .{ }^{20}$

The results of the chemical composition and loss on ignition of the silica gel are presented in Table 3. As expected, silica is the major component and comprises $91.6 \%$ of the sample mass. Other oxides present in significant amounts include $\mathrm{Al}_{2} \mathrm{O}_{3}(2.1 \%)$ and $\mathrm{SO}_{3}(1.6 \%)$. The elevated level of silica in the sample illustrates the effectiveness of the extraction method and corroborates the measured pozzolanic activity. The $\mathrm{SO}_{3}$ is derived from the organic material present in the rice husk ash.

Table 3. The chemical composition (\% mass) of the dry silica gel (xerogel)

\begin{tabular}{cc}
\hline Compound & Composition \\
\hline $\mathrm{SiO}_{2}$ & 91.6 \\
$\mathrm{Al}_{2} \mathrm{O}_{3}$ & 2.1 \\
$\mathrm{SO}_{3}$ & 1.6 \\
$\mathrm{Fe}_{2} \mathrm{O}_{3}$ & 0.1 \\
$\mathrm{~K}_{2} \mathrm{O}$ & $<0.1$ \\
Loss on ignition & 4.7 \\
\hline
\end{tabular}

Figure 1 shows the results of silica gel granulometry measurements. The material studied has an average particle size of $220 \mathrm{~nm}$. The specific mass of the dry silica gel (xerogel) was $2756 \mathrm{~kg} / \mathrm{m}^{3}$. It is important to note that the sample was not mechanically ground, but instead was manually ground in a porcelain mortar with a rubber tipped pestle to break up the biggest lumps. Therefore, it would not be possible to reproduce the granulometry of particles contained in the gel.

The X-ray diffraction pattern shown in Figure 4 reveals that the silica gel is amorphous and completely free of sodium chloride, proving the effectiveness of the extraction process. This data corroborates the infrared spectroscopy results. Given that the pozzolanic activity increases with greater silica content, silica gel from the rice husk ash has great potential for use as a pozzolan in cementitious-based materials.

The use of scanning electron microscopy by secondary electrons permitted an analysis of the morphology of the silica gel particles. It

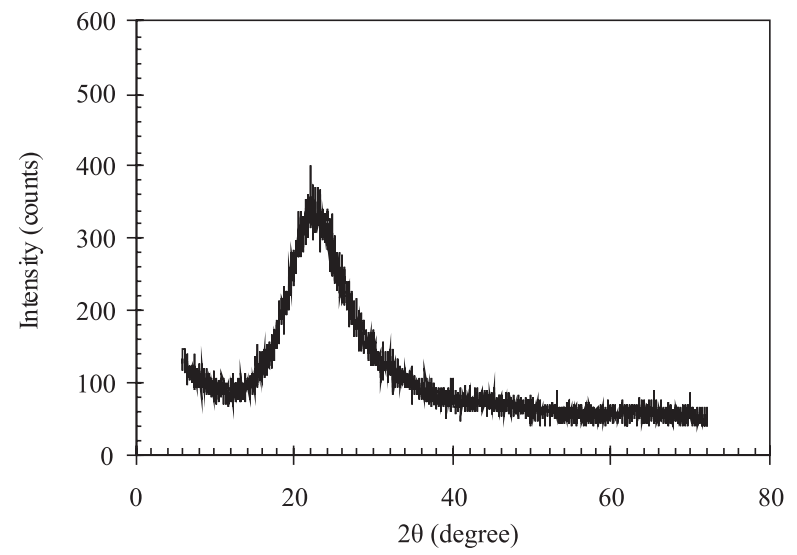

Figure 4. The X-ray diffraction data for the silica gel

was not possible to perform the analysis with silica suspended in the gel. Therefore, an analysis was performed with a kiln-dried sample that was manually ground in a porcelain mortar (Figure 5). In this case, the micrograph shows that individual silica grains could not be observed. Instead, the silica grouped into spherical clusters, forming an irregular and cohesive surface.

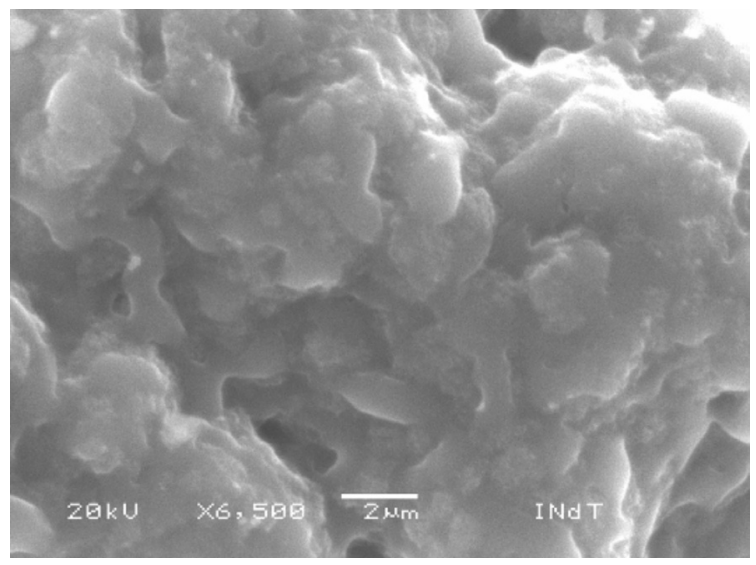

Figure 5. A layer of fine silica gel (a) and silica xerogel (b)

\section{Characterization of the cement-based pastes}

Figure 6 shows the changes in the average p1 paste compressive strength values over time. The obtained results indicate that the substitution of cement by silica gel always corresponds to a significant (by statistical analyses) strength increases in relation to the paste p1-0.0. It is notable that the increased strength is already significant after 3 days of curing for pastes p1-2.5 and p1-5.0, indicating an initially rapid kinetic reaction. This behavior is also apparent in the evolution of resistance in pastes containing silica gel compared to paste p1-0.0 after 3 and 7 days. The obtained results show the elevated pozzolanic activity of the silica gel and corroborate the values that were obtained in the study by modified Chapelle test, related in the previous item. These observations show that the pozzolanic activity of the silica gel is similar to the silica fume and nano- $\mathrm{SiO}_{2}$ activities, which has been reported by numerous authors. ${ }^{21,22}$

Figure 7 presents the average compressive strengths of pastes $\mathrm{p} 1$ and $\mathrm{p} 2$. As expected, an increase in the w/s ratio corresponds to a reduction in resistance. The action of the silica gel in the $\mathrm{p} 2$ pastes corresponds to the same effects on kinetics and amplitude verified in the results of the 1 pastes. As can be observed in Figure 7, the compressive strengths of the both $\mathrm{p} 1$ and $\mathrm{p} 2$ pastes are not influenced by $\mathrm{w} / \mathrm{s}$ relation variations. 


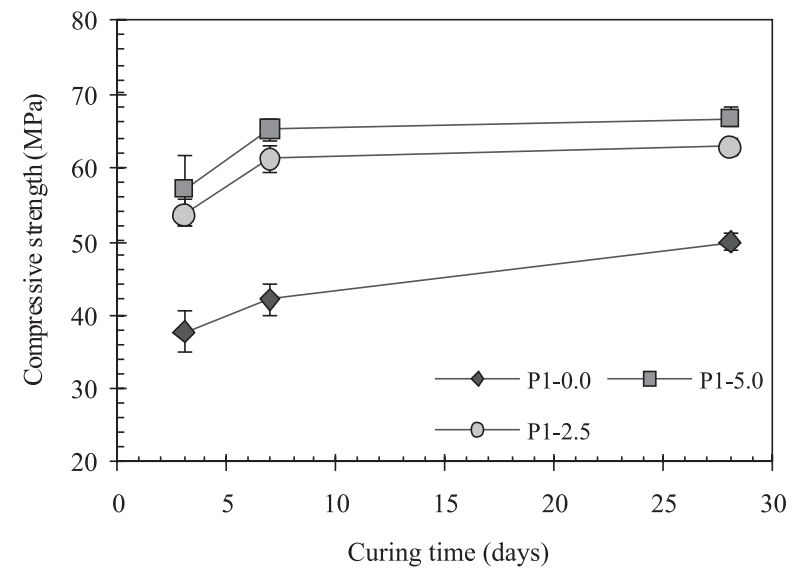

Figure 6. The evolution of the compressive strength in the $p-1$ pastes

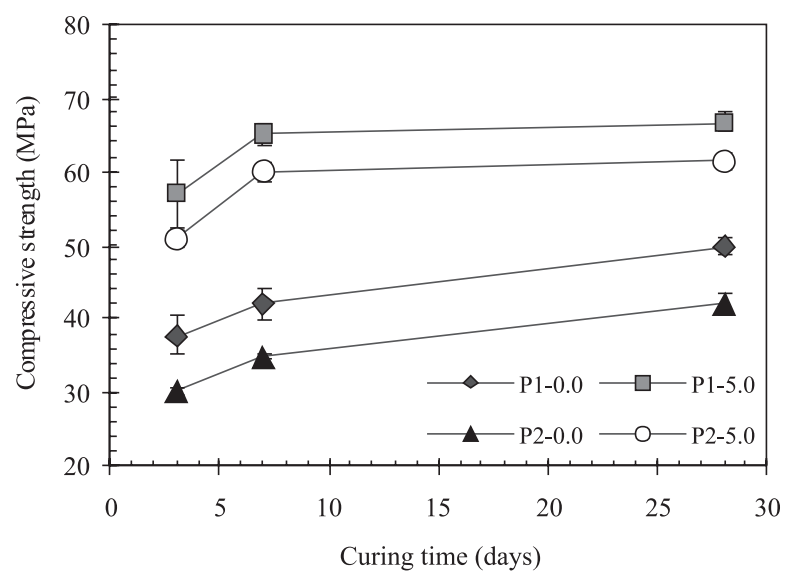

Figure 7. The influence of the $w / s$ ratio on the compressive strength of the pastes

\section{CONCLUSIONS}

Based on the results presented in this work, it can be concluded that: the silica obtained as a gel by chemical extraction was composed of high purity, nanometer-scale particles that had an amorphous structure. This result confirmed the elevated pozzolanic activity in the material. These characteristics were obtained without burning at high temperatures and after grinding the rice husk ash (the raw material) for only $30 \mathrm{~min}$. Partially substituting Portland cement by silica gel, obtained through a hydrothermal process, in cement pastes provided significantly increased compressive strength over 28 days, with the increase being most expressive in the first few days.

\section{SUPPLEMENTARY MATERIAL}

Contains Figure 1S, freely accessible and available at http:// quimicanova.sbq.org.br, in PDF format.

\section{ACKNOWLEDGMENTS}

The authors thank the Nokia Institute of Technology - AM (INDT), the Structures Laboratory and the Center for Catalysis (NUCAT) of the COPPE/UFRJ, the Macromolecules Institute (IMA/ UFRJ) for the completion of the analytical and mechanical tests and the agencies FAPEAM, Capes and CNPq for financial assistance.

\section{REFERENCES}

1. Mehta, P. K.; Pitt, N.; Resour. Recov. Conserv. 1976, 2, 23.

2. Hanafi, S.; Abo-El-Enein, S. A.; Ibrahim, D. M.; El-Hemaly, S. A.; Thermochim. Acta 1980, 37, 137.

3. James, J.; Subba Rao, M.; Cem. Concr. Res. 1996, 16, 296.

4. Della, V. P.; Khun, I.; Hotza, D.; Quim. Nova 2001, 24, 778.

5. Della, V. P.; Hotza, D.; Quim. Nova 2006, 29, 1175.

6. Kalapathy, U.; Proctor, A. S.; Cereal Chem. 1999, 75, 484.

7. Kalapathy, U.; Proctor, A. S.; Shultz, J.; Bioresour. Technol. 2000, 73, 257.

8. Kalapathy, U.; Proctor, A. S.; Shultz, J.; J. Chem. Technol. Biotechnol. 2000, 75, 464 .

9. Kalapathy, U.; Proctor, A. S.; Shultz, J.; Bioresour. Technol. 2002, 85, 285.

10. Hench, L. L.; West, J. K.; Chem. Rev. 1990, 90, 33.

11. Iler, R. K.; The chemistry of silica - Solubility, polymerization, colloid and surface properties, and Biochemistry, John Wiley \& Sons: New York, 1976.

12. Alexander, G. B.; Heston, W. M.; Iler, R. K.; J. Phys. Chem. 1954, 58, 453.

13. Chaves, M. R. M. C.; Tese de Doutorado, Universidade de São Paulo, Brasil, 2008.

14. Cordeiro, G. C.; Toledo Filho, R. D.; Tavares, L. M.; Fairbairn, E. M. R.; Cem. Concr. Compos. 2008, 30, 410.

15. Scrivener, K.; Kirkpatrick, R. J.; Cem. Concr. Res. 2008, 38, 128.

16. Cordeiro, G. C.; Toledo Filho, R. D.; Fairbairn, E. M. R.; Mater. Struct. 2009, 42, 983.

17. Associação Brasileira de Normas Técnicas; Cimento Portland comum, NBR 5732, Rio de Janeiro, 1991.

18. Liou, T. H.; Chang, W. F.; Lo, J. J.; Ind. Eng. Chem. Res. 1997, 36, 568.

19. Raverdy, M.; Brivot, F.; Paillère, A. M.; Bron, R.; 7e Congrés Internatinal de la Chimie des Ciments, Paris, France, 1980.

20. Cordeiro, G. C.; Toledo Filho, R. D.; Fairbairn, E. M. R.; Quim. Nova 2009, 32, 82 .

21. Malhotra, V. M.; Mehta, P. K.; Pozzolanic and Cementitious Materials, $1^{\text {st }}$ ed., Gordon and Breach Publishers: Amsterdam, 1996.

22. Qing, Y.; Zenan, Z.; Deyu, K.; Rongshen, C.; Constr. Build. Mater. 2007, $21,539$. 


\section{PRODUCTION OF SILICA GEL FROM RESIDUAL RICE HUSK ASH}

\section{Samantha Pinheiro Buás de Lima}

Faculdade de Tecnologia, Universidade Federal do Amazonas, Av. Gal. Rodrigo Octávio Jordão Ramos, 3000, 69077-000 Manaus -AM, Brasil Raimundo Pereira de Vasconcelos e Otávio Augusto Paiva

Departamento de Construção, Universidade Federal do Amazonas, Campus Universitário - Setor Norte, Coroados I, 69077-001 Manaus - AM, Brasil

\section{Guilherme Chagas Cordeiro*}

Laboratório de Engenharia Civil, Universidade Estadual do Norte Fluminense Darcy Ribeiro, Av. Alberto Lamego, 2000, 28013-602 Campos dos Goytacazes - RJ, Brasil

\section{Márcia Rodrigues de Morais Chaves}

Departamento de Engenharia Química, Escola Politécnica, Universidade de São Paulo, Av. Prof. Lineu Prestes, 580, B1. 18, 05424-970 São Paulo - SP, Brasil

\section{Romildo Dias Toledo Filho e Eduardo de Moraes Rego Fairbairn}

Instituto Alberto Luiz de Coimbra de Pós-graduação e Pesquisa de Engenharia, Universidade Federal do Rio de Janeiro, CP 68506, 21941-972 Rio de Janeiro - RJ, Brasil

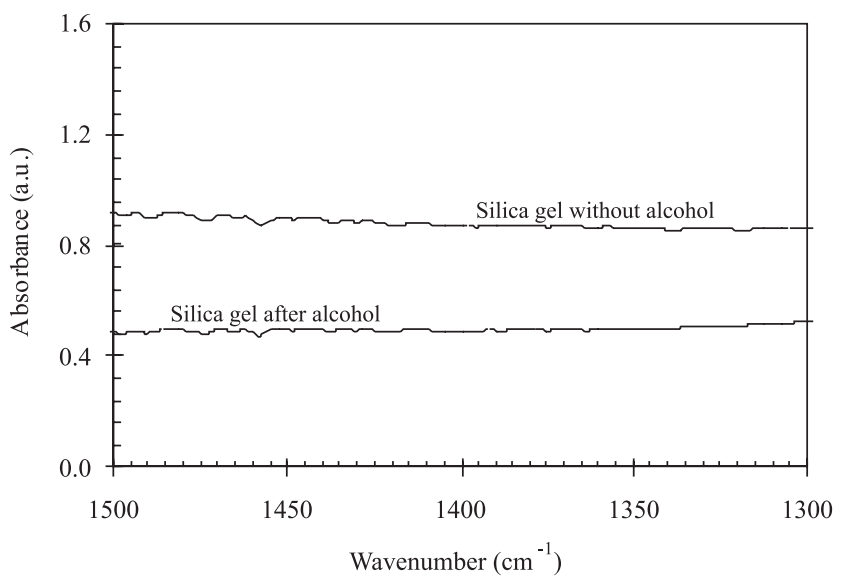

Figure 1S. Detail of the infrared spectra with wavenumbers between 1300 and $1500 \mathrm{~cm}^{-1}$ 